\title{
The Emotional Cost of Distance: Geographic Social Network Dispersion and Post- Traumatic Stress among Survivors of Hurricane Katrina
}

Katherine Ann Morris ${ }^{\mathrm{a}}$ and Nicole M. Deterding ${ }^{\mathrm{b}}$

${ }^{a}$ Harvard University Department of Sociology, William James Hall, 33 Kirkland Street, Cambridge, MA 02138

${ }^{b}$ University of Wisconsin-Madison, Institute for Research on Poverty

\section{Acknowledgements}

We thank Mary Waters, Asad Asad, Mariana Arcaya, Jean Rhodes, and three anonymous reviewers for comments on this paper. This research was supported by the Resilience in Survivors of Katrina Project (NIH grants R01 HD057599 and R01 HD046162, the National Science Foundation, and the MacArthur Foundation). We hereby affirm that our work was conducted in line with the requirements of the Institutional Review Board of Harvard University. 


\begin{abstract}
Rationale: Social networks offer important emotional and instrumental support following natural disasters. However, displacement may geographically disperse network members, making it difficult to provide and receive support necessary for psychological recovery after trauma.
\end{abstract}

Objectives: We examine associations between distance to network members and post-traumatic stress using survey data, and identify potential mechanisms underlying this association using indepth qualitative interviews.

Methods: We use longitudinal, mixed-methods data from the Resilience in Survivors of Katrina (RISK) Project to capture the long-term effects of Hurricane Katrina on low-income mothers from New Orleans. Baseline surveys occurred approximately one year before the storm and follow-up surveys and in-depth interviews were conducted five years later. We use a sequential explanatory analytic design. With logistic regression, we estimate the association of geographic network dispersion with the likelihood of post-traumatic stress. With linear regressions, we estimate the association of network dispersion with the three post-traumatic stress sub-scales. Using maximal variation sampling, we use qualitative interview data to elaborate identified statistical associations.

Results: We find network dispersion is positively associated with the likelihood of posttraumatic stress, controlling for individual-level socio-demographic characteristics, exposure to hurricane-related trauma, perceived social support, and New Orleans residency. We identify two social-psychological mechanisms present in qualitative data: respondents with distant network members report a lack of deep belonging and a lack of mattering as they are unable to fulfill obligations to important distant ties. 
Conclusion: Results indicate the importance of physical proximity to emotionally-intimate network ties for long-term psychological recovery.

Keywords: Mental Illness; Post-Traumatic Stress; Natural Disaster; Social Support; Egocentric Social Networks; Mixed Methods; Network Dispersion 


\section{The Emotional Cost of Distance: Geographic Social Network Dispersion and Post- Traumatic Stress among Survivors of Hurricane Katrina}

Hurricane Katrina caused massive destruction, loss of human life, and long-term housing displacement. Approximately 1.2 million individuals were displaced from the Gulf Coast region, and almost $80 \%$ of New Orleans evacuated before the storm (Fussell, Curtis, \& DeWaard, 2014).

By 2006, New Orleans recovered half its pre-Katrina population, reaching three-quarters by 2012 (Fussell \& Lowe, 2014). Evacuation and relocation strategies available to Hurricane Katrina survivors negatively impacted social networks and traditional kinship care arrangements (Asad, 2014; McCarthy-Brown \& Waysdorf, 2009). Many residents were relocated with little choice of destination and often without their close friends or family, due to limited access to transportation, financial resources, and time to prepare (Eisenman, Cordasco, Asch, Golden, \& Glik, 2007). Households with the fewest resources were least likely to keep their families together during evacuation and relocation processes (Fussell, 2006), geographically dispersing their social networks (Hurlbert, Beggs, \& Haines, 2006). In this paper, we examine the association between social network characteristics and post-traumatic stress disorder (PTSD) following Hurricane Katrina. We focus on network dispersion in particular, including in-depth interview data to suggest mechanisms by which dispersion affects psychological distress.

\section{Network Disruption and Function after Natural Disaster}

Network disruption—whether following natural disaster (Galea, Nandi, \& Vlahov, 2005), adverse social contexts such as war or political upheaval (Hall, Bonanno, Bolton, \& Bass 2014), or life events such as divorce (Milardo, 1987) or foster care placement (Perry, 2006)—is associated with increased psychological distress, including anxiety, depression, and PTSD. While primary stressors following disaster include witnessing destruction and death, secondary 
stressors are associated with long-term, indirect consequences like diminished financial resources and access to medical care. Weakened social support from network disruption is a key secondary stressor following disaster (Lock et al., 2012). Natural disasters disrupt networks through the experience of collective trauma and mass displacement. Collective trauma is the shared experience of a traumatic event, which can facilitate bonding and new relationships, but often hampers reciprocal exchange when individuals are unable to offer support given their own need (Kaniasty \& Norris, 1993, 1995). Mass displacement disrupts networks by physically separating survivors from their communities and routine contacts (Hurlbert et al., 2006). Even those who return may find both the physical environment and demographic composition of the community changed (Groen \& Polivka, 2010).

Social networks are crucial conduits of emotional and instrumental support that buffers against psychological distress in the short-term after disaster and aids psychological recovery in the long-term (Barnshaw \& Trainor, 2006; Galea et al., 2005; Hurlbert, Haines, \& Beggs, 2000; Reid \& Reczek, 2011). Research demonstrates that perceived emotional social support is protective against psychological disorders (Adeola \& Picou, 2014; Charuvastra \& Cloitre, 2008; Paxson, Fussell, Rhodes, \& Waters, 2012; Weems et al., 2007), while network disruption and loss of support is positively associated with risk of PTSD (Fredman et al., 2010; Hall et al., 2014; Hall, Murray, Galea, Canetti, \& Hobfoll, 2015). For example, geographic network dispersion is a key form of network disruption linked to PTSD. Bland et al. (1997) find that earthquake survivors whose displacement increased distance from their social relationships were more likely to experience psychological distress. However, increased distance does not necessitate disruption or dissolution, especially given social media and other new digital communication technologies (Phan \& Airoldi, 2015). The association of post-disaster PTSD with network dispersion in the 
Internet age remains an open question. We hypothesize that network dispersion is positively associated with PTSD after Hurricane Katrina. We further hypothesize that this association is moderated by New Orleans residency versus continued displacement.

\section{Geographic Network Dispersion and Social Support}

While social commentators suggest the Internet reduces the effect of distance on relationship quality, research demonstrates that digital communication only marginally affects how individuals maintain relationships (Mok, Wellman, \& Carrasco, 2010). Even today, distance to ties may remain negatively associated with frequency and quality of social interactions. Proximity to network members "fosters frequent contact, densely knit connections, mutual awareness of problems, and easy delivery of aid" (Wellman \& Wortley, 1990, p. 568), predicting emotional and instrumental social support (Hurlbert et al., 2000). Proximity also increases emotional intimacy between social ties due to more frequent interaction (Lawton, Silverstein, \& Bengtson, 1994).

This does not mean all distant social ties are weak or all proximate ties are intimate. Distant ties are often kin-based, representing "latent or sentimental relations" (Fischer, 1982, p. 169). Silverstein and Bengston (1997, p. 442) find that intimate-but-distant social relationships are those "in which functional exchange is absent, but where high levels of affinity may hold the potential for future exchange." Were distant ties not satisfying, they might be discontinued, “since local associates 'cost' less and distant ones 'cost' more, people find their distant ones more rewarding, on the average, than their nearer ones" (Fischer, 1982, p. 172). It follows that distance to intimate ties reduces access to instrumental support during periods of stress and may even exacerbate psychological distress. We hypothesize the association between network dispersion and PTSD is moderated by perceived emotional support. 


\section{Mechanisms Linking Geographic Network Dispersion and Mental Health}

We evaluate whether network dispersion is positively associated with psychological distress after Katrina and aim to understand the mechanisms of this association. In doing, we extend research on the so-called "stress-buffering-hypothesis," which suggests social ties ameliorate the effects of stress exposure on health outcomes (Cohen \& Wills, 1985). Researchers suggest social networks may affect physical and mental health through four categories of mechanisms: person-to-person exposure to infection or toxins; access to material resources or practical assistance; social influence and control; and emotional social support (Berkman, Glass, Brissette, \& Seeman, 2000). While these mechanisms are often described, they are rarely identified empirically (Thoits, 2011; Uchino, Cacioppo, \& Kiecolt-Glaser, 1996). By combining quantitative data on networks with qualitative interview data, we identify two social mechanisms by which network dispersion affects psychological health in the wake of disaster: belonging and mattering.

Belonging occurs through shared activities and discussions of important matters, producing feelings of acceptance and inclusion (Cutrona, 1990) and protecting against loneliness (Hawkley \& Cacioppo, 2010). It is also linked to emotional social support (Lin, Woelfel, \& Light, 1985; Thoits, 2011). Lack of belonging is a key symptom of what Erikson (1978, pp. 131, 187) describes as "disaster-related collective trauma." Expanding from the definition of collective trauma cited above, Erikson highlights "a gradual realization that the community no longer exists as an effective source of support and that an important part of the self has disappeared" (pp. 154). His interviewees relate loss of community and deep belonging to network disruption, saying: "You don't have any friends around, people around, like we had before" and "I don’t know where any of my friends are now" (pp. 196-7). We examine whether 
this mechanism persists across distance even in the Internet age.

Mattering refers to the positive feeling individuals get from fulfilling role expectations when they are relied upon for assistance, indicating they are important to others (France \& Finney, 2009). Mattering provides a sense of purpose, meaning in life, and self-worth (Thoits 2011: 148), which is protective of PTSD following natural disaster (Feder et al., 2013).

However, the strain caused by role expectations and obligations has also been referred to as the “dark side" of social networks (Kawachi \& Berkman, 2001, p. 463). We examine whether the inability fulfill obligations due to distance results in role strain and a lack of mattering (Rook, 1990), producing psychological distress.

\section{Data and Methods}

We draw data from the Resilience in Survivors of Katrina (RISK) Project, a mixedmethods, longitudinal study examining the long-term effects of natural disaster on low-income parents living in New Orleans before the storm. The study began in 2003 as Opening Doors Louisiana, a randomized-controlled trial of a community college scholarship intervention. When Hurricanes Katrina and Rita halted the Opening Doors evaluation, baseline data were repurposed to become RISK (Barrow, Richburg-Hayes, Rouse, \& Brock, 2013). Given Opening Doors eligibility criteria, the baseline sample is disproportionately female, African-American, and receiving some form of government assistance.

RISK used a nested mixed-method study design, surveying and interviewing the same individuals (Small, 2011, p. 69). Researchers conducted two post-Katrina telephone surveys of Opening Doors baseline participants and two waves of qualitative interviews with a subsample of survey respondents. Qualitative interviewees were chosen purposively to vary mental health characteristics and their post-hurricane location: New Orleans or Texas (Lowe \& Rhodes, 2013). 
Qualitative interviews were restricted to women, as the overwhelming majority of Opening Doors participants were female. The surveys and interviews measure similar concepts to facilitate mixed-methods analysis. The second post-Katrina survey (PK2) added questions to capture respondents' social connections, including their biological or adopted children, household members, and social network ties. Here, we report data from baseline and PK2 surveys and the second wave of qualitative interviews. Together, these data offer a unique opportunity to assess the association of social network characteristics and social support with the long-term psychological distress experienced following a natural disaster.

Opening Doors Louisiana collected pre-disaster data from 1,019 low-income parents in 2003 and 2005. 752 respondents from the baseline sample, including 702 women, completed the PK2 telephone survey in 2009-2010 for a total, unweighted response rate of 71\%. Sixty-three women also completed an in-depth, semi-structured qualitative interview. In order to ensure comparability between quantitative and qualitative data, we restrict our quantitative analysis to female PK2 respondents. We exclude 44 of the 702 women with missing geographic information. For all other missing data $(<10 \% ; N=48)$, we conducted multiple imputation by chained equations using the "mi impute" command in Stata 14, producing an analytic sample of 658 (White, Royston, \& Wood, 2011). We used item-level imputation for all scale and index measures (Gottschall, West, \& Enders, 2012; Shrive, Stuart, Quan, \& Ghali, 2006). We restrict qualitative analyses to interviews occurring within 12 months of the PK2 survey $(N=43)$, as networks evolve with members' changing obligations and routine activities (Small, Deeds Pamphile, \& McMahan, 2015). We used two-sample $t$-tests to determine whether the qualitative sample differed from the quantitative sample, finding comparability across all covariates except that the qualitative sample is slightly older. 


\section{Quantitative Measures}

Post-traumatic stress symptomology. We measure post-traumatic stress symptomology (PTSS) using the Impact of Event Scale-Revised (IES-R), a 22-item self-report scale that measures distress from a specific event (Weiss, 2007; Weiss \& Marmar, 1997). The IES-R assesses the likelihood of PTSD by asking how much distress respondents felt in the previous week due to things such as memories or nightmares about the event. The IES-R includes three subscales: avoidance; hyperarousal; and intrusion. Avoidance is characterized by emotional numbing and feeling as if the event were not real, attempts to remove the event from memory, and explicitly avoiding reminders or associated emotions. Individuals with a high avoidance score will typically avoid people, places, and situations associated with the event. Hyperarousal is characterized by feelings of irritability or anger, difficulty concentrating or sleeping, and hypervigilance, typified by feeling "watchful and on-guard.” Intrusion is characterized by distracting memories or images, acting or feeling as if back at the time of the event, constant reminders of the event, or nightmares. Responses to each item range from 0 ("never") to 4 (“extremely"). We create a scale by averaging the 22 items. PTSS is coded as a dummy variable; an IES-R score of 1.5 or higher indicates a high risk of having PTSD (Creamer, Bell, \& Failla, 2003). Reliability of the full IES-R scale on Cronbach's $\alpha$, is .95; on the avoidance subscale, .85; on the hyperarousal subscale, .89; and on the intrusion subscale, .91.

Social network measures. The RISK Project's social network module uses a name generator to determine the size of respondents' networks and name interpreters to collect information about each network member. Networks consist of the respondent (ego) and the persons (alters) directly connected to her. The name generator was adopted from the General Social Survey (GSS) “important matters" network, also called the "core discussion network," 
which was originally hypothesized to consist of the social ties most likely to influence opinions, provide social support, and enhance well-being (Burt, 1984, p. 317). The name generator asks respondents, "From time to time, most people discuss important matters with other people. Looking back over the last six months, who are the people with whom you discussed matters important to you?" Respondents name up to five people and the module continues with several name interpreters to elaborate the relationships.

We construct five social network measures from these interpreters: network size, ranging from 0 to 5 ; average frequency of communication with network alters, ranging from 1 ("less than once a month") to 4 (“daily"); proportion of alters who are kin; proportion of alters the respondent knew before Katrina; and geographic network dispersion, defined as the proportion of alters living 100 kilometers or more from the respondent. This dispersion measure is consistent with previous research on social support and exchange (Fischer, 1982; Hurlbert et al., 2000) and is a common threshold between every day and long-distance travel in transportation literature (Kowald \& Axhausen, 2015). All network measures except size were standardized.

Covariates. We assess hurricane exposure using two measures that capture disasterrelated stressors shown to be most predictive of PTSD (Chan \& Rhodes, 2014; Norris \& Wind, 2009). The first is whether the respondent had a friend or family member who died as a result of Hurricanes Katrina or Rita. The second is an exposure to hurricane trauma index using a sum of eight questions adapted from another survey of Hurricane Katrina evacuees (Brodie, Weltzien, Altman, Blendon, \& Benson, 2006). The questions include: not having enough fresh water and food; feeling like one's life was in danger; lacking necessary medicine and medical care for self and family members; and lacking knowledge about the safety of their children and other family. Reliability of the scale, measured using Cronbach's alpha, is .78. 
Since poor mental health before the hurricane may increase susceptibility to posttraumatic stress, we control for baseline psychological distress. Our baseline measure is the Kessler K-6 Scale, used in several other studies of Hurricane Katrina victims (Kessler et al., 2010). The six items ask respondents whether they experienced feelings such as "hopelessness" or "nervousness" in the last 30 days. Responses range from 0 ("none of the time") to 4 ("all of the time"). The total score is the sum of all six items ( $\alpha=.78)$. Scores of 8 to 12 indicate probable mild to moderate mental illness (MMI) while scores of 13 to 24 indicate serious mental illness (SMI). We code the scale into three categories: no mental illness; MMI; and SMI.

We measure perceived emotional social support at baseline using the Social Provisions Scale, which asks, "Do you agree with the following statements about your current relationships with family and friends..." (Cutrona \& Russell, 1987). The scale includes eight items such as, "there are people I know will help me if I need it." Responses range from 1 ("strongly disagree") to 4 ("strongly agree"). Negative items were reverse coded and items were averaged to obtain a total score. The scale ranges from to 0 to 4 , with higher scores indicating higher support $(\alpha=.75)$.

Additionally, we control for sociodemographic covariates, including New Orleans residency. Race is coded as black (1) or non-black (0). Age is measured in years. Marital status is measured as married or cohabitating with a romantic partner (1) or not (0). Number of children is all children between the ages of 0 and 17 living in the respondents' household at the time of the interview, top-coded at 4. Income is measured as the log of total household income last month. We also control for the number of months between when Hurricane Katrina made landfall and the day of the survey interview since time may increase the likelihood of psychological recovery.

\section{Analytic Strategy}

We adopt a sequential explanatory analytic design (Ivankova, Creswell, \& Stick, 2006), 
using qualitative data to elaborate statistical models. Our quantitative analyses include two steps. First, in Table 2, we use logistic regression models to predict the likelihood of PTSS. Model 1 is the baseline model. Model 2 adds network characteristics. Model 3 tests the hypothesis that New Orleans as residency moderates the association between network dispersion and PTSS whereas Model 4 tests the hypothesis that perceived social support moderates this association. Second, in Table 3, we use linear regression models to predict each of the three PTSS subscales, which is a robustness check to acquire a more detailed understanding of the association between network dispersion and PTSS. We might expect those with a high IES-R/PTSS avoidance score to have greater network dispersion due to a conscious effort to avoid distressing memories prompted by face-to-face interactions with persons they knew before the storm. If network dispersion differentially predicts the avoidance subscale compared to hyperarousal and intrusion, this could indicate that dispersion is the result rather than a cause of PTSS.

After modeling the main quantitative finding - the relationship between network dispersion and likelihood of PTSS — we examined qualitative data to better understand it. We used "maximum variation" sampling, limiting ourselves to qualitative cases with the largest variation on the independent variable of interest (Caracelli \& Greene, 1993; Flyvbjerg, 2006). Using information from the social network module, we selected interview cases belonging to two groups: those with the largest proportion of distant ties $(N=7$, mean distance $>500 \mathrm{~km})$ and those with only proximate ties $(N=24$, mean distance $=0 \mathrm{~km})$. We then wrote respondent-level thematic memos for each interview, focusing on the interview modules where women discussed family, friends, and acquaintances. Based on preliminary inductive analysis, we focused on textual evidence of two concepts suggested by the literature: belonging and mattering. We also compared themes for respondents whose surveys indicated PTSS and those whose did not. The 
findings we present result from cross-case analysis of 31 cases.

\section{Results}

\section{Social Network Dispersion and Post-Traumatic Distress: Quantitative Evidence}

Table 1 reports descriptive statistics for the variables in our quantitative models for the full analytic sample $(N=658)$ and by PTSS status. The full analytic sample has relatively small networks with an average of 2.21 alters. On average, these networks consist of kin, alters they knew before the hurricane, alters they communicate with on a daily basis, and proximate alters within 100 kilometers. The last column displays the $p$-values from two-sample $t$-tests for each variable comparing the mean among respondents without PTSS $(N=415)$ to those with PTSS $(N$ =243). Respondents with PTSS are older, more likely to be African-American, less likely to be married, have a lower monthly income, have a higher hurricane trauma index score, more likely to have lost a friend or relative during the hurricane, have lower perceived social support, have fewer kin in their network, and a greater proportion distant alters.

[Table 1 here]

Table 2 shows results from logistic regression models predicting PTSS. Model 1 includes individual-level socio-demographic characteristics, exposure to hurricane-related traumas, and baseline psychological distress. Consistent with previous research, age, race, baseline psychological distress, exposure to hurricane-related traumas, and death of a friend or relative significantly predict the likelihood of PTSS. Model 2 adds perceived social support and structural and compositional social network characteristics. A standard deviation increase in the proportion of distant alters is associated with a $21.9 \%$ increase in the log odds of PTSS in this model. As seen in Table 1, the standard deviation of proportion distant alters is 0.35 . For a 
network of three, the difference of 0.35 units is approximately the difference of one distant alter versus all alters living nearby. This model confirms that network dispersion positively predicts the likelihood of PTSS when controlling for socio-demographic characteristics and classic factors associated with hurricane experience and recovery (Chan \& Rhodes, 2014; Paxson et al., 2012). Additionally, we find that network dispersion positively predicts the likelihood of PTSS above and beyond perceived social support. Models 3 and 4 demonstrate the association is not moderated by living in New Orleans or perceived social support. While this contradicts previous theory suggesting perceived social support moderates the effect of network characteristics on mental health (House, 1987), it is consistent with empirical research on Hurricane Katrina (Lowe, Chan, \& Rhodes, 2010; McLaughlin et al., 2011; Paxson et al., 2012). Table 3 indicates that the network dispersion coefficient is similar and in the correct direction but not significantly associated with any of the three PTSS subscales, which suggests the relationship cannot be explained by a differential association with the avoidance subscale.

[Tables 2 and 3 here]

\section{Why Does Network Dispersion Predict Post-Traumatic Distress? Qualitative Evidence}

Survey data indicate that the geographic dispersion of significant social relationships is associated with PTSS after natural disaster. Our analysis also ruled out return to New Orleans, perceived social support, or reverse causality due to avoidance symptoms as explanations for this association. We now turn to interview data for suggestions of mechanisms linking distant alters to psychological distress. How does distance shape social relationships key to psychological recovery?

Building a "new family." Empirical work linking social networks to mental health typically frames social support as proffered by significant others, though Thoits (2011) theorizes 
that secondary others may also matter. Among interviewees with dispersed core networks, we do find evidence of new, proximate social connections made after Katrina. For example, 39-yearold Melissa, a divorced mother of two, lived in Houston at the time of interview. She described "being away from family, and not having that support system, having to develop a new family out here" as the hardest thing about life in the year after Katrina. By the interview-four years after the hurricane — she described a set of Houston friends as "very, very close, like extended family." Yet, despite success in building fulfilling relationships, she yearned for return to New Orleans, where her mother, grandmother, and best friend, identified on the name generator, lived. Like Melissa, the majority of interviewees developed new supportive and reciprocal relationships following the hurricane. Regarding a new friend in Houston, Tasha, a 36-year old mother of four, reported: "If I need her for something, I can go to her. If she needs me for something, she can come to me. No matter what it is." Thirty-two year old Nancy described a new neighbor as "like a sister" with whom she exchanged childcare when needed. These new relationships were largely not mentioned on the network name generator during survey administration, but appeared to offer respondents important day-to-day instrumental and emotional support.

Perhaps particularly for this sample of low-income mothers, respondents rely on nearby instrumental support such as picking-up children from school. Even women indicating a proximate network in the survey described the importance of new friends and loose connections as they dealt with the disaster and adjusted to life that followed. Interviews also suggest that respondents receive emotional support, like listening and offering advice about how to navigate interpersonal issues at home or at work, from these new relationships. These data are consistent with Model 4 in Table 2 indicating perceived social support does not attenuate the relationship 
between geographic network distance and PTSS, since respondents appear to draw instrumental and emotional support from secondary others.

The Emotional Cost of Distance. While interview respondents clearly value these new relationships, they discuss ties to distant network alters in qualitatively different terms, highlighting the emotional cost of distance. Qualitative responses suggest that psychological strain associated with geographically dispersed networks is most closely tied to two mechanisms from the social support literature: belonging and mattering.

Belonging — emotional comfort and acceptance within longtime relationships—is hypothesized to link social support and mental health even during settled times. Following Katrina, interviewees vividly described the emotional strain they felt when removed from the comfort of their closest friends and family. While Melissa, above, built new relationships "like family" in Houston, she also described continuing issues with sleep, unusual aches and pains, and anxiety, linking these symptoms to being away from her closest social ties, reporting "I think I still suffer some anxiety about what happened. I find myself at moments feeling sad or angry, and [do] not really know why. But I would say it would probably be linked to that tearing away from family and what happened in the storm."

Like the "tearing away" Melissa describes, a common metaphor for this mechanism was "uprooting." Kristin, a 30-year-old mother of two, lived in New Orleans at the time of interview, but highlighted the emotional strain she felt when far from her community for the three months she was displaced to San Antonio: "You're just being pulled out of your natural roots, like a tree. You pull a tree out at the natural roots, and how is it going to grow? And that's basically all you're thinking about when you're out there, and you're scared that you're going to have to do it again.” Kristin's survey indicates she continues to suffer from PTSS, and in the interview, she 
reports that thoughts of future hurricanes — and future uprooting — continue to cause emotional distress.

Similarly, Tasha, a 36-year-old mother of four living in Houston, described the lingering effects of distance from those returning to New Orleans: "My mom is depressed. I suffer with it. I mean, basically everybody who went through that shit is suffering with it." Tasha's survey indicates she continues to experience PTSS, and she reported that she thinks about the hurricane "Every day. I think about what I left and the change that it brought on my family and friends, the memories you'll never get back, the people you never get back.” In short, a lack of deep belonging appears to continue to affect those with distant primary networks.

Interview data also suggest role strain was a key experience of distance from primary ties. Mattering results when we meet others' expectations of us and successfully perform the social roles with which we identify. These women mothered their children every day, but the social roles of daughter and granddaughter also appeared particularly salient. When distance prevented fulfilling the caring obligations associated with these roles, respondents reported psychological stress.

For instance, the main reason Melissa is "determined to get back home" to New Orleans is to help her mother care for her grandmother, who lost both legs following diabetes complications. Melissa speaks to her mother on the phone frequently and her grandmother sends postcards, but she reports that, as a good daughter, "I just don't want the burden to be solely on my mom." From Houston, Melissa is physically unable to relieve her mother's burden.

Network dispersion also produced the strain of conflicting role obligations. Thirty-six year old Anna returned to New Orleans under pressure from her mother and aunt "to help out with the family," but regretted not choosing St. Louis with her father: "I'm the only one that 
really talks to my dad, the closest one to my father. The only time [my little brother] calls is when he needs something. I call my daddy for advice. I call my daddy just to say hello. I just call my dad." Anna's father was the one person mentioned on her network name generator, and as he struggled with depression and isolation, their distance weighed heavily on her as well.

Finally, qualitative data indicate that role strain emanated both from significant others' stated expectations and respondents' own expectations of themselves. Even in the absence of explicit pressure, many women described feeling guilt and regret when they were unable to meet distant others" needs. If social obligations are the "dark side" of social networks, it appears distance only emphasizes the strain obligations can produce.

\section{Discussion}

This paper answers the question: "What difference does the spatial distribution of ties make?" (Fischer, 1982, p. 173) We find that geographic dispersion is positively associated with risk of PTSS. This association is not moderated by perceived social support as suggested by literature on social structure and support (House, 1987) and literature on the stress-bufferinghypothesis (Weems et al., 2007). Further, we do not find the main association is moderated by living in New Orleans, despite previous research indicating post-Katrina relocation negatively predicted mental health (Lowe, Willis, \& Rhodes, 2014). Based on analysis of interview data, we suggest two potential mechanisms for the association between network dispersion and psychological distress: belonging and mattering.

Echoing Erikson's Everything in Its Path (1978, p. 233), we find that “when one's communal surround disappears, and with it a feeling of belonging and identity, one tends to feel less intact personally.” Interviewees reporting dispersed core discussion networks do not lack 
proximate social ties. Instead, they describe their proximate and distant ties in qualitatively different terms. They report material support and companionship from secondary others-new friendships and even "new family" built since the hurricane-yet they long for the deep belonging they felt when embedded among significant others pre-Katrina. Interviewees with dispersed networks also report emotional strain from an inability to meet obligations toward distant ties, especially kin. These data suggest that distance to significant others named to the core discussion network decreases feelings of belonging and mattering and increases feelings of longing and burden in the wake of disaster.

By capitalizing on the RISK project's unique data, we build on growing attention to integrating qualitative and quantitative data in social network research (Bellotti, 2014; Domínguez \& Hollstein, 2014). Contextualizing statistical models with qualitative data, we illustrate how individuals "perceive and define their friends, the nature and content of their relationships, and the opportunities and constraints offered by local networks" in the wake of a disaster (Bellotti, 2014, p. 77). An important contribution of this work is that respondents derive instrumental and emotional social support from individuals who go unmentioned on the GSS "important matters" network name generator. However, we find both quantitative and qualitative evidence that those mentioned on the name generator constitute an intimate group of significant others who continue to shape individuals' emotional recovery from disaster. This combination of data also suggests that new and latent secondary ties are essential immediately following a crisis, but that continued recovery and distinct support is provided by an intimate group of core ties (Perry \& Pescosolido, 2012).

\section{Limitations}

While we contribute to an understanding of the relationship between social networks and 
psychological distress, our work has limitations. First, the RISK sample is not representative of New Orleans residents at the time of the storm. Generalizing from this sample is problematic, particularly given that low-income women in urban areas have smaller, denser networks than average (Domínguez \& Watkins, 2003; Fischer, 1982). Nonetheless, understanding the recovery trajectories of this population is particularly important. Young, low-income, mothers of color are especially vulnerable to disasters and their sequelae (Bolin, 2007; Fothergill \& Peek, 2004).

They were also most likely to have been displaced by damage from Hurricanes Katrina and Rita (Groen \& Polivka, 2010), and thus may be most likely to suffer the effects of network dispersion.

Second, we cannot establish causality using the survey database alone. The network name generator was not administered pre-Katrina, so we cannot control for baseline network characteristics to establish that network dispersion resulted from the storm. We also cannot firmly establish whether network dispersion was a cause of PTSD, as we argue, or a result of it. Negative social interactions, asymmetrical resource exchange, and residential instability may result in the loss of proximate alters, and this loss rather than distance to remaining alters may increase the likelihood of PTSD (Fredman et al., 2010; King, Taft, King, Hammond, \& Stone, 2006). Finally, we control for perceived emotional support but do not control for average tie strength between ego and alters, which could introduce omitted variable bias. Respondents may feel less emotionally close to distant alters, increasing the likelihood of PTSD among persons with dispersed networks. However, our qualitative analysis supports the directional argument we suggest, as does prior research on network dispersion (Bland et al., 1997).

Third, RISK uses the GSS “important matters" name generator, which is susceptible to question-ordering effects (Pustejovsky \& Spillane, 2009) and topic-alter dependency (Bearman \& Parigi, 2004). The protocol records respondents' social networks halfway through the survey, 
immediately after soliciting their experiences during the hurricane and "opinions about life in New Orleans these days." It could be that respondents interpreted the hurricane or life in New Orleans as "important matters," emphasizing alters currently residing there. However, there is little support for this in the data. In interviews, respondents are asked "Is there anyone you talk to about the storm?" and often describe persons who do not appear to be alters mentioned on the name generator.

Finally, this work and other research suggest that the name generator does not capture the full range of relationships. The question solicits small, homogenous, kin-centered networks with strong ties and relatively high density (Marsden, 1987), which are hypothesized to provide key emotional support (Burt, 1984). It does not capture other weak or peripheral ties that also convey support (Small, 2013). Additionally, given the six-month time frame specified in the name generator, we may not capture ties that previously provided support or continue to provide companionship. However, the six-month time frame is intended to increase respondent accuracy and capture ties most essential for stress-buffering in times of crisis, the focus of this paper (Marin \& Hampton, 2007; van der Poel, 1993).

\section{Conclusion}

Despite limitations, our work builds upon previous research on social relationships and mental health in the post-disaster context by drawing from a unique, longitudinal source of quantitative and qualitative data. We argue that distance to core discussion network members is positively associated with PTSS five years after Katrina because it decreases feelings of belonging and mattering. While respondents appear to receive social support from post-Katrina relationships, proximity to the intimate ties solicited by the GSS "important matters" name 
generator facilitates the deep belonging and mattering that buffers against distress. Our work reinforces a need to distinguish between the material and emotional dimensions of social support and the importance of elucidating varied and nuanced mechanisms of emotional support inadequately captured by quantitative perceived emotional support scales. We also underscore how network characteristics both promote and impair health and highlight the value of mixed methods in studies of social networks and health. 


\section{References}

Adeola, F. O., \& Picou, J. S. (2014). Social capital and the mental health impacts of hurricane Katrina: assessing long-term patterns of psychosocial distress. International Journal of Mass Emergencies and Disasters, 32(1), 121-156.

Asad, A. L. (2014). Contexts of reception, post-disaster migration, and socioeconomic mobility. Population and Environment, 36(3), 279-310. http://doi.org/10.1007/s11111-014-0221-4

Barnshaw, J., \& Trainor, J. (2006). Race, Class, and Capital amidst the Hurricane Katrina Diaspora. In Understanding Katrina: Perspectives from the Social Sciences (pp. 150166). Social Science Research Council.

Barrow, L., Richburg-Hayes, L., Rouse, C. E., \& Brock, T. (2013). Paying for Performance: The Education Impact of a Community College Scholarship Program for Low-Income Adults. Chicago, IL: Federal Reserve Bank of Chicago.

Bearman, P., \& Parigi, P. (2004). Cloning Headless Frogs and Other Important Matters: Conversation Topics and Network Structure. Social Forces, 83(2), 535-557. http://doi.org/10.1353/sof.2005.0001

Bellotti, E. (2014). Qualitative Networks: Mixed Methods in Sociological Research. Routledge. Berkman, L. F., Glass, T., Brissette, I., \& Seeman, T. E. (2000). From social integration to health: Durkheim in the new millennium. Social Science \& Medicine, 51, 843-857.

Bland, S. H., O’Leary, E. S., Farinaro, E., Jossa, F., Krogh, V., Violanti, J., \& Trovisan, M. (1997). Social Network Disturbances and Psychological Distress following Earthquake Evacuation. Journal of Nervous and Mental Disease, 185(3), 188-195.

Bolin, B. (2007). Race, Class, Ethnicity, and Disaster Vulnerability. In Handbook of Disaster Research (pp. 113-129). Springer New York. Retrieved from 
http://link.springer.com/chapter/10.1007/978-0-387-32353-4_7

Brodie, M., Weltzien, E., Altman, D., Blendon, R. J., \& Benson, J. M. (2006). Experiences of Hurricane Katrina evacuees in Houston shelters: implications for future planning. American Journal of Public Health, 96(8), 1402-1408.

Burt, R. S. (1984). Network items and the general social survey. Social Networks, 6(4), 293-339. http://doi.org/10.1016/0378-8733(84)90007-8

Caracelli, V. J., \& Greene, J. C. (1993). Data Analysis Strategies for Mixed-Method Evaluation Designs. Educational Evaluation and Policy Analysis, 15(2), 195-207. http://doi.org/10.3102/01623737015002195

Chan, C. S., \& Rhodes, J. E. (2014). Measuring Exposure in Hurricane Katrina: A Meta-Analysis and an Integrative Data Analysis. PLoS ONE, 9(4). http://doi.org/10.1371/journal.pone.0092899

Charuvastra, A., \& Cloitre, M. (2008). Social Bonds and Posttraumatic Stress Disorder. Annual Review of Psychology, 59, 301-328. http://doi.org/10.1146/annurev.psych.58.110405.085650

Cohen, S., \& Wills, T. A. (1985). Stress, social support, and the buffering hypothesis. Psychological Bulletin, 98(2), 310-357. http://doi.org/10.1037/0033-2909.98.2.310

Creamer, M., Bell, R., \& Failla, S. (2003). Psychometric properties of the Impact of Event Scale-Revised. Behaviour Research and Therapy, 41(12), 1489-1496. http://doi.org/10.1016/j.brat.2003.07.010

Cutrona, C. E. (1990). Stress and Social Support—in Search of Optimal Matching. Journal of Social and Clinical Psychology, 9(1), 3-14. http://doi.org/10.1521/jscp.1990.9.1.3

Cutrona, C. E., \& Russell, D. W. (1987). The provisions of social relationships and adaptation to 
stress. Advances in Personal Relationships, 1(1), 37-67.

Domínguez, S., \& Hollstein, B. (2014). Mixed Methods Social Networks Research: Design and Applications. Cambridge University Press.

Domínguez, S., \& Watkins, C. (2003). Creating Networks for Survival and Mobility: Social Capital Among African-American and Latin-American Low-Income Mothers. Social Problems, 50(1), 111-135. http://doi.org/10.1525/sp.2003.50.1.111

Eisenman, D. P., Cordasco, K. M., Asch, S., Golden, J. F., \& Glik, D. (2007). Disaster Planning and Risk Communication with Vulnerable Communities: Lessons From Hurricane Katrina. American Journal of Public Health, 97(Supplement_1), S109-S115. http://doi.org/10.2105/AJPH.2005.084335

Erikson, K. T. (1978). Everything in Its Path: Destruction of Community in the Buffalo Creek Flood. New York: Simon \& Schuster.

Feder, A., Ahmad, S., Lee, E. J., Morgan, J. E., Singh, R., Smith, B. W., ... Charney, D. S. (2013). Coping and PTSD symptoms in Pakistani earthquake survivors: Purpose in life, religious coping and social support. Journal of Affective Disorders, 147(1-3), 156-163. http://doi.org/10.1016/j.jad.2012.10.027

Fischer, C. S. (1982). To Dwell Among Friends: Personal Networks in Town and City. University of Chicago Press.

Flyvbjerg, B. (2006). Five Misunderstandings about Case-Study Research. Qualitative Inquiry, 12(2), 219-245. http://doi.org/10.1177/1077800405284363

Fothergill, A., \& Peek, L. A. (2004). Poverty and Disasters in the United States: A Review of Recent Sociological Findings. Natural Hazards, 32(1), 89-110. http://doi.org/10.1023/B:NHAZ.0000026792.76181.d9 
France, M. K., \& Finney, S. J. (2009). What Matters in the Measurement of Mattering? A Construct Validity Study. Measurement and Evaluation in Counseling and Development, 42(2), 104-120. http://doi.org/10.1177/0748175609336863

Fredman, S. J., Monson, C. M., Schumm, J. A., Adair, K. C., Taft, C. T., \& Resick, P. A. (2010). Associations Among Disaster Exposure, Intimate Relationship Adjustment, and PTSD Symptoms: Can Disaster Exposure Enhance a Relationship? Journal of Traumatic Stress, 23(4), 446-451. http://doi.org/10.1002/jts.20555

Fussell, E. (2006). Leaving New Orleans: Social Stratification, Networks, and Hurricane Evacuation. In Understanding Katrina: Perspectives from the Social Sciences (pp. 150166). Social Science Research Council.

Fussell, E., Curtis, K. J., \& DeWaard, J. (2014). Recovery migration to the City of New Orleans after Hurricane Katrina: a migration systems approach. Population and Environment, 35(3), 305-322. http://doi.org/10.1007/s11111-014-0204-5

Fussell, E., \& Lowe, S. R. (2014). The impact of housing displacement on the mental health of low-income parents after Hurricane Katrina. Social Science \& Medicine, 113, 137-144. http://doi.org/10.1016/j.socscimed.2014.05.025

Galea, S., Nandi, A., \& Vlahov, D. (2005). The Epidemiology of Post-Traumatic Stress Disorder after Disasters. Epidemiologic Reviews, 27(1), 78-91. http://doi.org/10.1093/epirev/mxi003

Gottschall, A. C., West, S. G., \& Enders, C. K. (2012). A Comparison of Item-Level and ScaleLevel Multiple Imputation for Questionnaire Batteries. Multivariate Behavioral Research, 47(1), 1-25. http://doi.org/10.1080/00273171.2012.640589

Groen, J. A., \& Polivka, A. E. (2010). Going Home after Hurricane Katrina: Determinants of 
Return Migration and Changes in Affected Areas. Demography, 47(4), 821-844.

Hall, B. J., Murray, S. M., Galea, S., Canetti, C., \& Hobfoll, S. E. (2015). Loss of Social Resources Predicts Incident Posttraumatic Stress Disorder During Ongoing Political Violence within the Palestinian Authority. Social Psychiatry and Psychiatric Epidemiology, 50(4), 561-568. http://doi.org/ 10.1007/s00127-014-0984-z

Hall, B. J., Bonanno, G. A., Bolton, P., \& Bass, J. K. (2014). A Longitudinal Investigation of Changes in Social Resources Associated with Psychological Distress Among Kurdish Torture Survivors Living in Northern Iraq. The Journal of Traumatic Stress, 27(4), 446453. http://doi.org/10.1002/jts.21930

Hawkley, L. C., \& Cacioppo, J. T. (2010). Loneliness Matters: A Theoretical and Empirical Review of Consequences and Mechanisms. Annals of Behavioral Medicine, 40(2), 218227. http://doi.org/10.1007/s12160-010-9210-8

House, J. S. (1987). Social support and social structure. Sociological Forum, 2, 135-146.

Hurlbert, J. S., Beggs, J. J., \& Haines, V. A. (2006). Bridges over Troubled Waters: What are the Optimal Networks for Katrina's Victims? In Understanding Katrina: Perspectives from the Social Sciences. Social Science Research Council. Retrieved from http://understandingkatrina.ssrc.org/Hurlbert_Beggs_Haines/

Hurlbert, J. S., Haines, V. A., \& Beggs, J. J. (2000). Core Networks and Tie Activation: What Kinds of Routine Networks Allocate Resources in Nonroutine Situations? American Sociological Review, 65, 598-618.

Ivankova, N. V., Creswell, J. W., \& Stick, S. L. (2006). Using Mixed-Methods Sequential Explanatory Design: From Theory to Practice. Field Methods, 18(1), 3-20. http://doi.org/10.1177/1525822X05282260 
Kaniasty, K., \& Norris, F. H. (1993). A test of the social support deterioration model in the context of natural disaster. Journal of Personality and Social Psychology, 64(3), 395408. http://doi.org/10.1037/0022-3514.64.3.395

Kaniasty, K., \& Norris, F. H. (1995). Mobilization and Deterioration of Social Support Following Natural Disasters. Current Directions in Psychological Science (WileyBlackwell), 4(3), 94-98.

Kawachi, D. I., \& Berkman, D. L. F. (2001). Social ties and mental health. Journal of Urban Health, 78(3), 458-467. http://doi.org/10.1093/jurban/78.3.458

Kessler, R. C., Green, J. G., Gruber, M. J., Sampson, N. A., Bromet, E., Cuitan, M., ... Zaslavsky, A. M. (2010). Screening for serious mental illness in the general population with the K6 screening scale: results from the WHO World Mental Health (WMH) survey initiative. International Journal of Methods in Psychiatric Research, 19(S1), 4-22. http://doi.org/10.1002/mpr.310

King, D. W., Taft, C., King, L. A., Hammond, C., \& Stone, E. R. (2006). Directionality of the Association between Social Support and Posttraumatic Stress Disorder: A Longitudinal Investigation1. Journal of Applied Social Psychology, 36(12), 2980-2992. http://doi.org/10.1111/j.0021-9029.2006.00138.x

Kowald, M., \& Axhausen, K. W. (Eds.). (2015). Social Networks and Travel Behaviour. Ashgate Publishing, Ltd.

Lawton, L., Silverstein, M., \& Bengtson, V. (1994). Affection, Social Contact, and Geographic Distance between Adult Children and Their Parents. Journal of Marriage and Family, 56(1), 57-68. http://doi.org/10.2307/352701

Lin, N., Woelfel, M. W., \& Light, S. C. (1985). The Buffering Effect of Social Support 
Subsequent to an Important Life Event. Journal of Health and Social Behavior, 26, 247263.

Lock, S., Rubin, G. J., Murray, V., Rogers, M. B., Amlôt, R., \& Williams, R. (2012). Secondary stressors and extreme events and disasters: a systematic review of primary research from 2010-2011. PLoS Currents, 4. http://doi.org/10.1371/currents.dis.a9b76fed1b2dd5c5bfcfc13c87a2f24f

Lowe, S. R., Chan, C. S., \& Rhodes, J. E. (2010). Pre-hurricane perceived social support protects against psychological distress: A longitudinal analysis of low-income mothers. Journal of Consulting and Clinical Psychology, 78(4), 551-560. http://doi.org/10.1037/a0018317

Lowe, S. R., \& Rhodes, J. E. (2013). Trajectories of Psychological Distress among Low-Income, Female Survivors of Hurricane Katrina. The American Journal of Orthopsychiatry, 83(2 0 3), 398-412. http://doi.org/10.1111/ajop.12019

Lowe, S. R., Willis, M., \& Rhodes, J. E. (2014). Health problems among low-income parents in the aftermath of Hurricane Katrina. Health Psychology, 33(8), 774-782. http://doi.org/10.1037/hea0000016

Marin, A., \& Hampton, K. N. (2007). Simplifying the Personal Network Name Generator Alternatives to Traditional Multiple and Single Name Generators. Field Methods, 19(2), 163-193. http://doi.org/10.1177/1525822X06298588

Marsden, P. V. (1987). Core Discussion Networks of Americans. American Sociological Review, $52,122-131$

McCarthy-Brown, S., \& Waysdorf, S. L. (2009). Katrina Disaster Family Law: The Impact of Hurricane Katrina on Families and Family Law. Ind. L. Rev., 42, 721.

McLaughlin, K. A., Berglund, P., Gruber, M. J., Kessler, R. C., Sampson, N. A., \& Zaslavsky, 
A. M. (2011). Recovery from PTSD following Hurricane Katrina. Depression and Anxiety, 28(6), 439-446. http://doi.org/10.1002/da.20790

Milardo, R. M. (1987). Changes in Social Networks of Women and Men Following Divorce: A Review. Journal of Family Issues, 8(1), 78-96. http://doi.org/10.1177/019251387008001004

Mok, D., Wellman, B., \& Carrasco, J. (2010). Does Distance Matter in the Age of the Internet? Urban Studies, 47(13), 2747-2783. http://doi.org/10.1177/0042098010377363

Norris, F. H., \& Wind, L. H. (2009). The Experience of Disaster: Trauma, Loss, Adversitities, and Community Effects. In Y. Neria \& S. Galea (Eds.), Mental Health and Disasters (pp. 29-44). Cambridge University Press.

Paxson, C., Fussell, E., Rhodes, J., \& Waters, M. (2012). Five years later: Recovery from posttraumatic stress and psychological distress among low-income mothers affected by Hurricane Katrina. Social Science \& Medicine, 74(2), 150-157. http://doi.org/10.1016/j.socscimed.2011.10.004

Perry, B. L. (2006). Understanding social network disruption: The case of youth in foster care. Social Problems, 53(3), 371. http://doi.org/http://dx.doi.org/10.1525/sp.2006.53.3.371

Perry, B. L., \& Pescosolido, B. A. (2012). Social Network Dynamics and Biographical Disruption: The Case of "First-Timers" with Mental Illness. American Journal of Sociology, 118(1), 134-175. http://doi.org/10.1086/666377

Phan, T. Q., \& Airoldi, E. M. (2015). A natural experiment of social network formation and dynamics. Proceedings of the National Academy of Sciences, 112(21), 6595-6600. http://doi.org/10.1073/pnas.1404770112

Pustejovsky, J. E., \& Spillane, J. P. (2009). Question-order effects in social network name 
generators. Social Networks, 31(4), 221-229. http://doi.org/10.1016/j.socnet.2009.06.001

Reid, M., \& Reczek, C. (2011). Stress and Support in Family Relationships after Hurricane Katrina. Journal of Family Issues, 32(10), 1397-1418. http://doi.org/10.1177/0192513X11412497

Rook, K. S. (1990). Parallels in the Study of Social Support and Social Strain. Journal of Social and Clinical Psychology, 9(1), 118-132. http://doi.org/10.1521/jscp.1990.9.1.118

Shrive, F. M., Stuart, H., Quan, H., \& Ghali, W. A. (2006). Dealing with missing data in a multiquestion depression scale: a comparison of imputation methods. BMC Medical Research Methodology, 6, 57. http://doi.org/10.1186/1471-2288-6-57

Silverstein, M., \& Bengtson, V. L. (1997). Intergenerational Solidarity and the Structure of Adult Child-Parent Relationships in American Families. American Journal of Sociology, 103(2), 429-60. http://doi.org/10.1086/231213

Small, M. L. (2011). How to Conduct a Mixed Methods Study: Recent Trends in a Rapidly Growing Literature. Annual Review of Sociology, 37(1), 57-86. http://doi.org/10.1146/annurev.soc.012809.102657

Small, M. L. (2013). Weak ties and the core discussion network: Why people regularly discuss important matters with unimportant alters. Social Networks, 35(3), 470-483. http://doi.org/10.1016/j.socnet.2013.05.004

Small, M. L., Deeds Pamphile, V., \& McMahan, P. (2015). How stable is the core discussion network? Social Networks, 40, 90-102. http://doi.org/10.1016/j.socnet.2014.09.001

Thoits, P. A. (2011). Mechanisms Linking Social Ties and Support to Physical and Mental Health. Journal of Health and Social Behavior, 52(2), 145-161. http://doi.org/10.1177/0022146510395592 
Uchino, B. N., Cacioppo, J. T., \& Kiecolt-Glaser, J. K. (1996). The relationship between social support and physiological processes: a review with emphasis on underlying mechanisms and implications for health. Psychological Bulletin, 119(3), 488-531.

van der Poel, M. G. M. (1993). Delineating personal support networks. Social Networks, 15(1), 49-70. http://doi.org/10.1016/0378-8733(93)90021-C

Weems, C. F., Watts, S. E., Marsee, M. A., Taylor, L. K., Costa, N. M., Cannon, M. F., ... Pina, A. A. (2007). The psychosocial impact of Hurricane Katrina: Contextual differences in psychological symptoms, social support, and discrimination. Behaviour Research and Therapy, 45(10), 2295-2306.

Weiss, D. S. (2007). The Impact of Event Scale: Revised. In P. J. P. Wilson \& P. C. S. Tang (Eds.), Cross-Cultural Assessment of Psychological Trauma and PTSD (pp. 219-238). Springer US. Retrieved from http://link.springer.com/chapter/10.1007/978-0-387-70990$1 \_10$

Weiss, D. S., \& Marmar, C. R. (1997). The Impact of Event Scale-Revised. In J. P. Wilson \& T. M. Keane (Eds.), Assessing psychological trauma and PTSD (pp. 399-411). New York, NY: Guilford Press.

Wellman, B., \& Wortley, S. (1990). Different Strokes from Different Folks: Community Ties and Social Support. The American Journal of Sociology, 96, 558-588.

White, I. R., Royston, P., \& Wood, A. M. (2011). Multiple imputation using chained equations: Issues and guidance for practice. Statistics in Medicine, 30(4), 377-399. http://doi.org/10.1002/sim.4067 
Table 1. Descriptive Statistics for Variables in Regression Models

\begin{tabular}{|c|c|c|c|c|c|c|c|c|}
\hline \multirow[b]{2}{*}{ Variables } & \multirow[b]{2}{*}{ Range } & \multicolumn{2}{|c|}{ Full Sample } & \multicolumn{2}{|c|}{ Without PTSS } & \multicolumn{2}{|c|}{ With PTSS } & \multirow[b]{2}{*}{$p$} \\
\hline & & Mean & $S D$ & Mean & $S D$ & Mean & & \\
\hline \multicolumn{9}{|l|}{ Dependent Variables } \\
\hline Post-Traumatic Stress Scale & 0,1 & 0.369 & 0.483 & & & & & \\
\hline Avoidance Sub-scale & 0,4 & 1.340 & 0.984 & & & & & \\
\hline Hyperarousal Sub-scale & 0,4 & 0.964 & 1.044 & & & & & \\
\hline Intrusion Sub-scale & 0,4 & 1.374 & 1.106 & & & & & \\
\hline \multicolumn{9}{|c|}{ Socio-Demographic Characteristics } \\
\hline Age at Baseline Years & 18,35 & 25.129 & 4.402 & 24.723 & 4.374 & 25.823 & 4.372 & 0.002 \\
\hline African-American & 0,1 & 0.860 & 0.347 & 0.810 & 0.393 & 0.947 & 0.225 & $<0.001$ \\
\hline Married / Cohabiting & 0,1 & 0.448 & 0.498 & 0.499 & 0.501 & 0.362 & 0.482 & 0.001 \\
\hline \# Children, Ages 0-17 & 0,4 & 1.778 & 0.984 & 1.769 & 0.978 & 1.794 & 0.995 & 0.748 \\
\hline Log of Monthly Income & $4.605,9.833$ & 7.594 & 0.775 & 7.646 & 0.780 & 7.505 & 0.759 & 0.053 \\
\hline \multicolumn{9}{|c|}{ Hurricane Experience and Recovery } \\
\hline \multicolumn{9}{|c|}{ Baseline Psychological Distress } \\
\hline Mild to Moderate & 0,1 & 0.173 & 0.379 & 0.152 & 0.360 & 0.210 & 0.408 & 0.058 \\
\hline Serious & 0,1 & 0.061 & 0.239 & 0.039 & 0.193 & 0.100 & 0.299 & 0.002 \\
\hline Hurricane Trauma Index & 0,8 & 3.070 & 2.246 & 2.513 & 2.018 & 4.021 & 2.301 & $<0.001$ \\
\hline Death of Friend/Relative & 0,1 & 0.413 & 0.493 & 0.337 & 0.473 & 0.543 & 0.499 & $<0.001$ \\
\hline Time to Follow-Up Months & $43.32,55.78$ & 46.045 & 2.805 & 46.107 & 2.796 & 45.940 & 2.821 & 0.461 \\
\hline Living in New Orleans & 0,1 & 0.705 & 0.456 & 0.728 & 0.446 & 0.667 & 0.472 & 0.098 \\
\hline \multicolumn{9}{|c|}{ Social Network and Support Characteristics } \\
\hline Perceived Social Support & $1.286,4$ & 3.210 & 0.442 & 3.252 & 0.419 & 3.136 & 0.472 & 0.002 \\
\hline Network Size & 1,5 & 2.214 & 1.184 & 2.260 & 1.165 & 2.136 & 1.214 & 0.193 \\
\hline Average Communication & 1,4 & 3.736 & 0.463 & 3.726 & 0.481 & 3.753 & 0.432 & 0.478 \\
\hline Proportion Kin & 0,1 & 0.675 & 0.383 & 0.695 & 0.368 & 0.640 & 0.406 & 0.078 \\
\hline Proportion Knew Before & 0,1 & 0.876 & 0.264 & 0.878 & 0.261 & 0.875 & 0.268 & 0.888 \\
\hline Proportion $\geq 100$ km & 0,1 & 0.230 & 0.349 & 0.203 & 0.326 & 0.275 & 0.383 & 0.012 \\
\hline Observations & \multicolumn{3}{|c|}{658} & \multicolumn{2}{|c|}{415} & \multicolumn{2}{|c|}{243} & \\
\hline
\end{tabular}

Note: Descriptive statistics were calculated using the first imputation data set. Unless otherwise noted, all variables are measured at the second postKatrina survey (PK2), approximately five years after the storm. The last column displays the $p$-values from two-sample $t$-tests for each variable comparing the mean among persons without probable post-traumatic stress $(N=415)$ to the mean among persons with probable post-traumatic stress $(N=243)$. 
Table 2. Odds Ratios from Logistic Regression Models Predicting Post-Traumatic Stress

\begin{tabular}{|c|c|c|c|c|}
\hline Variables & Model 1 & Model 2 & Model 3 & Model 4 \\
\hline \multicolumn{5}{|l|}{ Socio-demographic Characteristics } \\
\hline Age at Baseline & $\begin{array}{c}1.053^{*} \\
(1.010,1.097)\end{array}$ & $\begin{array}{c}1.051^{*} \\
(1.008,1.096)\end{array}$ & $\begin{array}{c}1.051^{*} \\
(1.008,1.096)\end{array}$ & $\begin{array}{c}1.050^{*} \\
(1.007,1.095)\end{array}$ \\
\hline African-American & $\begin{array}{c}3.044 * * \\
(1.562,5.931)\end{array}$ & $\begin{array}{c}2.698 * * \\
(1.378,5.285)\end{array}$ & $\begin{array}{c}2.699 * * \\
(1.378,5.287)\end{array}$ & $\begin{array}{c}2.672 * * \\
(1.364,5.237)\end{array}$ \\
\hline Married/Cohabiting & $\begin{array}{c}0.618^{*} \\
(0.421,0.907)\end{array}$ & $\begin{array}{c}0.644 * \\
(0.434,0.956)\end{array}$ & $\begin{array}{c}0.644 * \\
(0.434,0.955)\end{array}$ & $\begin{array}{c}0.648^{*} \\
(0.437,0.962)\end{array}$ \\
\hline \# Children, Ages 0-17 & $\begin{array}{c}0.992 \\
(0.828,1.188)\end{array}$ & $\begin{array}{c}0.994 \\
(0.828,1.193)\end{array}$ & $\begin{array}{c}0.993 \\
(0.828,1.193)\end{array}$ & $\begin{array}{c}0.992 \\
(0.826,1.191)\end{array}$ \\
\hline Log of Monthly Income & $\begin{array}{c}0.974 \\
(0.760,1.247)\end{array}$ & $\begin{array}{c}0.976 \\
(0.760,1.254)\end{array}$ & $\begin{array}{c}0.975 \\
(0.759,1.253)\end{array}$ & $\begin{array}{c}0.966 \\
(0.752,1.242)\end{array}$ \\
\hline \multicolumn{5}{|l|}{ Hurricane Experience and Recovery } \\
\hline Mild to Moderate & $\begin{array}{c}1.541^{+} \\
(0.968,2.452)\end{array}$ & $\begin{array}{c}1.534^{+} \\
(0.962,2.447)\end{array}$ & $\begin{array}{c}1.538^{+} \\
(0.964,2.455)\end{array}$ & $\begin{array}{c}1.539^{+} \\
(0.966,2.452)\end{array}$ \\
\hline Serious & $\begin{array}{c}2.776 * * \\
(1.312,5.870)\end{array}$ & $\begin{array}{c}2.796 * * \\
(1.304,5.998)\end{array}$ & $\begin{array}{c}2.795 * * \\
(1.302,5.999)\end{array}$ & $\begin{array}{c}2.778 * * \\
(1.292,5.973)\end{array}$ \\
\hline Hurricane Trauma Index & $\begin{array}{c}1.276 * * * \\
(1.175,1.387)\end{array}$ & $\begin{array}{c}1.285 * * * \\
(1.181,1.397)\end{array}$ & $\begin{array}{c}1.284 * * * \\
(1.181,1.396)\end{array}$ & $\begin{array}{c}1.284 * * * \\
(1.181,1.396)\end{array}$ \\
\hline Death of Friend/Relative & $\begin{array}{c}1.490^{*} \\
(1.038,2.139)\end{array}$ & $\begin{array}{c}1.521^{*} \\
(1.056,2.190)\end{array}$ & $\begin{array}{c}1.520^{*} \\
(1.055,2.189)\end{array}$ & $\begin{array}{c}1.522 * \\
(1.057,2.194)\end{array}$ \\
\hline Living in New Orleans & $\begin{array}{c}0.808 \\
(0.549,1.187)\end{array}$ & $\begin{array}{c}0.915 \\
(0.603,1.387)\end{array}$ & $\begin{array}{c}0.907 \\
(0.592,1.391)\end{array}$ & $\begin{array}{c}0.919 \\
(0.606,1.395)\end{array}$ \\
\hline Time to Follow-up & $\begin{array}{c}0.977 \\
(0.916,1.042)\end{array}$ & $\begin{array}{c}0.977 \\
(0.915,1.042)\end{array}$ & $\begin{array}{c}0.977 \\
(0.915,1.042)\end{array}$ & $\begin{array}{c}0.974 \\
(0.913,1.040)\end{array}$ \\
\hline \multicolumn{5}{|c|}{ Social Network and Support Characteristics } \\
\hline Perceived Social Support & $\begin{array}{c}0.813 \\
(0.542,1.221)\end{array}$ & $\begin{array}{c}0.817 \\
(0.536,1.246)\end{array}$ & $\begin{array}{c}0.817 \\
(0.536,1.245)\end{array}$ & $\begin{array}{c}0.817 \\
(0.535,1.248)\end{array}$ \\
\hline Network Size & & $\begin{array}{c}0.972 \\
(0.833,1.134)\end{array}$ & $\begin{array}{c}0.972 \\
(0.833,1.135)\end{array}$ & $\begin{array}{c}0.970 \\
(0.831,1.132)\end{array}$ \\
\hline Standardized Average Communication & & $\begin{array}{c}1.152 \\
(0.951,1.396)\end{array}$ & $\begin{array}{c}1.151 \\
(0.950,1.395)\end{array}$ & $\begin{array}{c}1.146 \\
(0.947,1.388)\end{array}$ \\
\hline Standardized Proportion Kin & & $\begin{array}{c}0.908 \\
(0.743,1.110)\end{array}$ & $\begin{array}{c}0.907 \\
(0.741,1.109)\end{array}$ & $\begin{array}{c}0.910 \\
(0.744,1.112)\end{array}$ \\
\hline Standardized Proportion Knew Before & & $\begin{array}{c}1.056 \\
(0.867,1.287)\end{array}$ & $\begin{array}{c}1.059 \\
(0.867,1.294)\end{array}$ & $\begin{array}{c}1.052 \\
(0.864,1.282)\end{array}$ \\
\hline Standardized Proportion $\geq 100 \mathrm{~km}$ & & $\begin{array}{c}1.219 * \\
(1.007,1.477)\end{array}$ & $\begin{array}{c}1.198 \\
(0.898,1.597)\end{array}$ & $\begin{array}{c}0.642 \\
(0.172,2.402)\end{array}$ \\
\hline \multicolumn{5}{|l|}{ Interactions } \\
\hline $\begin{array}{l}\text { Living in New Orleans } \times \text { Standardized } \\
\text { Proportion } \geq 100 \mathrm{~km}\end{array}$ & & & $\begin{array}{c}1.032 \\
(0.709,1.502)\end{array}$ & \\
\hline $\begin{array}{l}\text { Perceived Support } \times \text { Standardized } \\
\text { Proportion } \geq 100 \mathrm{~km}\end{array}$ & & & & $\begin{array}{c}1.227 \\
(0.809,1.861)\end{array}$ \\
\hline Constant & $\begin{array}{c}0.195 \\
(0.003,11.88)\end{array}$ & $\begin{array}{c}0.207 \\
(0.003,12.93)\end{array}$ & $\begin{array}{c}0.209 \\
(0.003,13.10)\end{array}$ & $\begin{array}{c}0.261 \\
(0.004,16.73)\end{array}$ \\
\hline Observations & 658 & 658 & 658 & 658 \\
\hline
\end{tabular}

Note: $95 \%$ confidence intervals are in parentheses

${ }^{+} p<.10 . * p<.05 . * * p<.01 . * * * p<.001$. 
Table 3. Ordinary Least Squares Regression Models Predicting Post-traumatic Stress Subscales

\begin{tabular}{|c|c|c|c|}
\hline Variables & $\begin{array}{c}\text { Model } 1 \\
\text { Avoidance } \\
\end{array}$ & $\begin{array}{c}\text { Model } 2 \\
\text { Hyperarousal } \\
\end{array}$ & $\begin{array}{l}\text { Model } 3 \\
\text { Intrusion } \\
\end{array}$ \\
\hline \multicolumn{4}{|l|}{ Socio-demographic Characteristics } \\
\hline Age at Baseline & $\begin{array}{c}1.014 \\
(0.997,1.030)\end{array}$ & $\begin{array}{c}1.019^{*} \\
(1.002,1.037)\end{array}$ & $\begin{array}{c}1.016^{+} \\
(0.998,1.035)\end{array}$ \\
\hline African-American & $\begin{array}{c}1.656 * * * \\
(1.331,2.060)\end{array}$ & $\begin{array}{c}1.280^{*} \\
(1.026,1.598)\end{array}$ & $\begin{array}{c}1.442 * * \\
(1.134,1.832)\end{array}$ \\
\hline Married/Cohabiting & $\begin{array}{c}0.857 * \\
(0.733,1.001)\end{array}$ & $\begin{array}{c}0.906 \\
(0.773,1.063)\end{array}$ & $\begin{array}{c}0.882 \\
(0.741,1.050)\end{array}$ \\
\hline \# Children, Ages 0-17 & $\begin{array}{c}0.987 \\
(0.918,1.061)\end{array}$ & $\begin{array}{c}1.009 \\
(0.937,1.087)\end{array}$ & $\begin{array}{c}0.983 \\
(0.907,1.066)\end{array}$ \\
\hline Log of Monthly Income & $\begin{array}{c}0.984 \\
(0.890,1.088)\end{array}$ & $\begin{array}{c}0.931 \\
(0.840,1.031)\end{array}$ & $\begin{array}{c}0.993 \\
(0.889,1.110)\end{array}$ \\
\hline \multicolumn{4}{|l|}{ Hurricane Experience and Recovery } \\
\hline Mild to Moderate & $\begin{array}{c}1.250 * \\
(1.034,1.511)\end{array}$ & $\begin{array}{c}1.177+ \\
(0.971,1.426)\end{array}$ & $\begin{array}{c}1.153 \\
(0.936,1.421)\end{array}$ \\
\hline Serious & $\begin{array}{c}1.477 * * \\
(1.093,1.996)\end{array}$ & $\begin{array}{c}1.662 * * \\
(1.218,2.268)\end{array}$ & $\begin{array}{c}1.897 * * * \\
(1.358,2.651)\end{array}$ \\
\hline Hurricane Trauma Index & $\begin{array}{c}1.102 * * * \\
(1.065,1.140)\end{array}$ & $\begin{array}{c}1.157 * * * \\
(1.118,1.198)\end{array}$ & $\begin{array}{c}1.142 * * * \\
(1.100,1.186)\end{array}$ \\
\hline Death of Friend/Relative & $\begin{array}{c}1.234 * * \\
(1.063,1.433)\end{array}$ & $\begin{array}{c}1.356 * * * \\
(1.163,1.580)\end{array}$ & $\begin{array}{c}1.353 * * * \\
(1.146,1.597)\end{array}$ \\
\hline Living in New Orleans & $\begin{array}{c}0.980 \\
(0.831,1.156)\end{array}$ & $\begin{array}{c}1.041 \\
(0.878,1.233)\end{array}$ & $\begin{array}{c}0.938 \\
(0.780,1.127)\end{array}$ \\
\hline Time to Follow-up & $\begin{array}{c}1.007 \\
(0.982,1.032)\end{array}$ & $\begin{array}{c}0.998 \\
(0.972,1.024)\end{array}$ & $\begin{array}{c}0.988 \\
(0.961,1.016)\end{array}$ \\
\hline \multicolumn{4}{|l|}{ Social Network and Support Characteristics } \\
\hline Perceived Social Support & $\begin{array}{c}0.971 \\
(0.821,1.147)\end{array}$ & $\begin{array}{c}0.923 \\
(0.778,1.095)\end{array}$ & $\begin{array}{c}1.023 \\
(0.850,1.232)\end{array}$ \\
\hline Network Size & $\begin{array}{c}0.992 \\
(0.933,1.054)\end{array}$ & $\begin{array}{c}0.983 \\
(0.924,1.047)\end{array}$ & $\begin{array}{c}0.976 \\
(0.912,1.044)\end{array}$ \\
\hline Standardized Average Communication & $\begin{array}{c}1.058 \\
(0.982,1.140)\end{array}$ & $\begin{array}{c}1.076+ \\
(0.997,1.162)\end{array}$ & $\begin{array}{c}1.049 \\
(0.966,1.140)\end{array}$ \\
\hline Standardized Proportion Kin & $\begin{array}{c}1.007 \\
(0.929,1.092)\end{array}$ & $\begin{array}{c}0.991 \\
(0.912,1.077)\end{array}$ & $\begin{array}{c}0.987 \\
(0.902,1.080)\end{array}$ \\
\hline Standardized Proportion Knew Before & $\begin{array}{c}0.973 \\
(0.899,1.052)\end{array}$ & $\begin{array}{c}1.002 \\
(0.925,1.086)\end{array}$ & $\begin{array}{c}0.994 \\
(0.911,1.085)\end{array}$ \\
\hline Standardized Proportion $\geq 100 \mathrm{~km}$ & $\begin{array}{c}1.059 \\
(0.981,1.144)\end{array}$ & $\begin{array}{c}1.039 \\
(0.961,1.124)\end{array}$ & $\begin{array}{c}1.061 \\
(0.974,1.155)\end{array}$ \\
\hline Constant & $\begin{array}{c}1.170 \\
(0.231,5.918)\end{array}$ & $\begin{array}{c}1.799 \\
(0.343,9.434)\end{array}$ & $\begin{array}{c}2.169 \\
(0.359,13.08)\end{array}$ \\
\hline Observations & 658 & 658 & 658 \\
\hline
\end{tabular}

Note: $95 \%$ confidence intervals are in parentheses.

${ }^{+} p<.10 . * p<.05 . * * p<.01 . * * * p<.001$. 